\title{
RECONSTRUCTED GRANITE AS AN INSULATING MATERIAL.
}

[Being the report of the Franklin Institute, through its Committee on Science and the Arts, on the invention of Thomas Wilkinson Blakey, of Keene, N. H., and Wm. Courtenay, of New York. Sub-Committee.-Geo. A. Hoadley, C. H. Bedell, Arthur J. Rowland, W. M. Stine.]

[No. 21 22.]

Hall of the FrankLin Institute, Philadelphia, November $7,1900$.

The Franklin Institute of the State of Pennsylvania for the Promotion of the Mechanic Arts, acting through its Committee on Science and the Arts, investigating the merits of the Reconstructed Granite Company's "reconstructed gianite used as an insulating material for electrical purposes," reports as follows:

Reconstructed granite is a manufactured product, produced substantially as follows: Natural granite chips are calcined by being brought to a high temperature and afterward pulverized. It is then thoroughly mixed with pulverized feldspar and kaolin in definite proportions; enough water is added to make the mixture plastic, and it is then moulded into the desired forms under heavy pressure. After being dried it is subjected to a temperature of about $3,000^{\circ}$ Fahrenheit, at which temperature it is fused into a homogeneous mass. When used for electrical purposes, the surface is given a vitrified glazing, which aids in increasing its insulating properties by rendering it less porous. The claims made for this material are as follows:

(I) It is absolutely fireproof:

(2) It resists the action of all solvents and acids except hydrofluoric, which attacks it superficially.

(3) It is frostproof.

(4) It is non-porous, and consequently does not absorb moisture.

(5) It has high crushing and tensile strength.

(6) It has high insulating qualities. 
In investigating this material, your committee has made use of, first, experimental tests, and, second, the testimony of extensive users of the various forms of insulation blocks produced.

From the tests made, the reports on the various claims are as follows :

Claim $1 .-$ A piece of broken insulator was heated until it became red' hot, when it was plunged immediately into cold water. The only observed effect was a slight checking in the glazing in an angle of the specimen.

Claim 2.-Found to be substantially correct.

Claim 3.-No tests were made of its resistance to the action of frost.

Claim 4.-A piece of the material was weighed in November, 1899 , and found to weigh. 1706.2 grains. It was then placed in water and kept there until October, 1900, when it was found to weigh $1719^{\circ} 2$ grains. It was then dried and lost all its moisture except ' 2 grain, weighing I706.4 grains. Computing the amount of absorption we found it to be 76 per cent. of the weight of the specimen.

Claim 5.-Three tests for crushing strength and four for tensile strength were made by a member of the committee, with the following results :

\section{CRUSHING.}

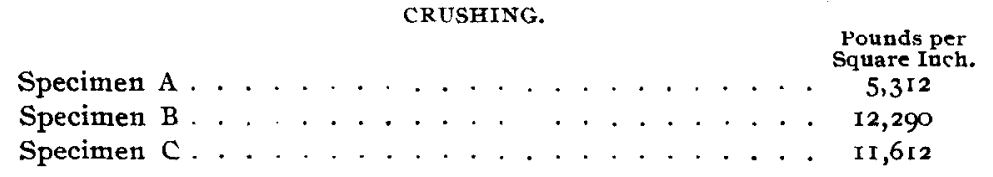

TENSILE STRENGTH.

Specimen I . . . . . . . . . . . . . $\begin{gathered}\text { Pounds per } \\ \text { Square Iuch }\end{gathered}$

Specimen $2 \ldots \ldots \ldots$

Specimen $3 \ldots \ldots$. . . . . . . . . . . . . . . . . . . . 973

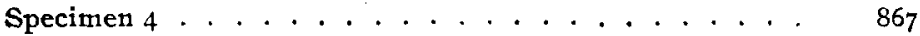

Claim 6.- The report of this test can best be given in a quotation from the report of the member making the test: "I tested the samples of 'reconstructed granite,' both with a megohm Weston voltmeter under 550 volts, and also with our D'Arsonval galvanometer and fifty silver chloride cells. 
One volt deflection on the voltmeter is equivalent to 550 megohms, while the D'Arsonval instrument registers thousands of megohms. The samples are beyond the range of either instrument before soaking. After removing the glaze and soaking in salt water for two weeks, we can just get a very slight movement of the needle on our megohm voltmeter. We are safe in saying that the ohmic resistance of these samples is very high."

The testimony of the different users consulted by your committee does not cover all the claims, but is in part as follows :

"We have been using it (reconstructed granite) for thirdrail insulators in large quantities, and have, therefore, sub. jected it to numerous tests in regard to the absorption of moisture, break-down qualities at different potentials, strength, etc., finding it to be extremely variable. In the case of absorption as much as 7 per cent. of its weight is often taken up, while in other instances it is as low as onehalf of I per cent. *** By thoroughly baking and drying out the material we have been able to get a resistance as high as 8 megohms, but upon subjecting it to steam for twenty-four hours, the resistance was as low as 20,000 ohms."

Another extensive user writes: "We use the reconstructed granite in connection with our railway equipments for several purposes. One is to support the panels in the resistance boxes, and to support the cast grid resistances to angle irons fastened under the car. For these purposes we find it a good insulator, and stronger than any vitrified brick that we are able to get hold of. We also use this granite in the controller as an arc deflector. *** Breaking the heavy currents that are necessary on heavy elevated work, that is, 250 ampères, is quite a problem, and we found nothing else that would do as well for a deflector as this granite." "It is also used extensively, I believe, altogether by the elevated roads in Brooklyn as an insulator for the third rail."

The tests and testimonies herein cited have caused your committee to believe that an invention of decided commer- 
cial importance has been made, and in consequence of this belief the Franklin Institute recommends that the John Scott Legacy Premium and Medal be awarded to Thomas Wilkinson Blakey, of Keene, N. H., and William Courtenay, of New York, N. Y., for their " Reconstructed Granite as a Material for Insulating Purposes."

Adopted at the stated meeting of the Committee on Science and the Arts, held Wednesday, December 5, 1900.

John Birkinbine, President.

Countersigned,

WM. H. WAHL, Secretary.

\author{
H. R. HEYL, \\ Chairman of the Committee on Science and the Arts.
}

\title{
NO'TES AND COMMENTS.
}

\section{PROTECTING BUILDINGS FROM FIRE BY A WATER CURTAIN.}

The Iron Age is authority for the statement that the method of protecting buildings from fire by the use of what is called a "water curtain," by which water can be caused to fall in a sheet all around the structure, is steadily growing in favor. The same journal conveys the information that the great building of the Public Library of Chicago is protected on this plan. The arrangement, which is extremely simple, is described as follows :

A 7 -inch steel water main is laid around the top of the structure, upon the broad stone table formed by the top of the coping, this pipe having connection with force pumps situated in the basement, and, through perforations properly arranged, insures the introduction of a substantial sheet of water from cornice to pavement, around the whole or any imperiled portion of the building. The arrangement of the system of piping is such as to permit of operating in prescribed sections; additional relays of smaller pipe are also placed in position above windows and doors in order to complete the curtaining of those points in the most serviceable manner, should the curtain in the main be broken by wind impinging against the building.

w.

\section{HOW SHOULD BOILER-HEATING SURFACES BE CALCULATED.}

In a paper lately presented to the American Society of Mechanical Engineers, Mr. C. W. Baker questions the correctness of the usual practice of computing the horse-power of steam boilers from the heating surface. He affirms that by the method usually followed, there results an error of from 7 to 17 per cent., which, he says, is due to the practice of taking the surface in contact with the water, instead of that in contact with the fire gases, as the heating surface. Where these surfaces are flat there will be no difference between 